\title{
Article \\ Halloysite and Laponite Hybrid Pigments Synthesis with Copper Chlorophyll
}

\author{
Bàrbara Micó-Vicent ${ }^{1, * \mathbb{D}}$, Esther Perales Romero ${ }^{2}$, Jorge Jordán-Núñez ${ }^{1}$ and Valentín Viqueira ${ }^{2}$ \\ 1 Departamento de Ingeniería Gráfica, Universitat Politècnica de València, Campus d'Alcoi, \\ 03801 Alcoy, Alicante, Spain; jorjornu@upv.es \\ 2 Departamento de Óptica Farmacología y Anatomía, Universidad de Alicante, \\ 03690 San Vicent del Raspeig, Alicante, Spain; esther.perales@mscloud.ua.es (E.P.R.); \\ valentin.viqueira@ua.es (V.V.) \\ * Correspondence: barmivi@upv.es
}

check for updates

Citation: Micó-Vicent, B.; Perales Romero, E.; Jordán-Núñez, J.; Viqueira, V. Halloysite and Laponite Hybrid Pigments Synthesis with Copper Chlorophyll. Appl. Sci. 2021, 11, 5568. https://doi.org/10.3390/ app11125568

Academic Editors: Jae-Hong Choi, Jorge Bañuelos Prieto and Rocco Furferi

Received: 8 April 2021

Accepted: 10 June 2021

Published: 16 June 2021

Publisher's Note: MDPI stays neutral with regard to jurisdictional claims in published maps and institutional affiliations.

Copyright: (c) 2021 by the authors. Licensee MDPI, Basel, Switzerland. This article is an open access article distributed under the terms and conditions of the Creative Commons Attribution (CC BY) license (https:/ / creativecommons.org/licenses/by/ $4.0 /)$.

\begin{abstract}
Sustainable and green materials have been studied in dye and pigment productions to reduce their environment impacts from being produced and applied. Although natural dyes are an excellent choice to move from agrowaste, some improvements must be made before they are applied given their poor fastness. One way of improving natural dye properties is their adsorption into nanoclay structures to give hybrid pigments. This work used tubular halloysite and laminar laponite to adsorb and stabilize natural copper chlorophyll. With a statistical design of experiments, we observed interactions between synthesis factors, such as $\mathrm{pH}$, ionic strength, and surfactant or silane modification. Cool hybrid pigments with high TSR (\%) values and a wide color range were obtained by using dispersions with only distilled water at room temperature. Successful chlorophyll adsorption on both nanoclay surfaces took place by XRD and DTA analyses. The maximum natural dye absorption for both nanoclay types took place under acid conditions, $\mathrm{pH} 3-4$, and in the presence of mordant. The TSR (\%) improved by the silane $\mathrm{pH}$ interaction, and halloysite hybrid pigments obtained higher TSR values than the laponite ones. Finally, a wide chromatic green color range was obtained with the surfactant modification in both nanoclays, and the color fastening was also improved in the hybrid pigments application. The samples generated with $10 \%$ of hybrid pigments from both nanoclays and an Epoxy bioresin, show higher colorfastness than the sample with the natural chlorophyll, due to the nanoclays-dye interaction and protection.
\end{abstract}

Keywords: halloysite; laponite; nanopigments; chlorophyll; statistical design of experiments; statistical analysis; UV-VIS; NIR; CIELAB; properties

\section{Introduction}

Circular and sustainable economy is a trending topic in product and process design. Industries and researchers are working to develop green products, and natural dyes are an example of such [1]. Their production is growing in South America, and their extraction from agricultural waste is successfully achieved [2,3]. Some of the advantages of natural fibers are they are non-toxic, they possess antioxidant activity, their medical applications and biodegradation capability, and they pose no environmental issues [4-6]. Chlorophyll is one of the most abundant biological pigments, and it abounds in eubacteria and plants [7]. Due to their properties, chlorophyll dyes (CDs) have been used in biomedical applications [8], complex applications as solar cell dyes [9,10] and supramolecular structures [11]. However, CDs are unstable to retaining their antioxidant activity when exposed to oxygen, high temperature, or light environments $[9,10]$.

One way of improving the stability of natural dyes like chlorophyll is their adsorption into inorganic structures like nanoclays. Laponite nanoclays have proven effectiveness in cationic dye adsorption. Laponite is a synthetic disk-shaped hectorite silicate of approximately $25 \mathrm{~nm}$ in diameter and $1 \mathrm{~nm}$ thickness. Particle aggregation and gel generation de- 
pend on dispersion conditions, such as concentration, $\mathrm{pH}$, temperature, etc., [12]. Laponite can be used as a host for natural dyes to protect them. It has been demonstrated to adsorb up to $93 \%$ of anthocyanin from jambolan fruit extract. In addition, anthocyanin-laponite hybrid pigments have antioxidant properties and can be used as colorimetric indicator material at $\mathrm{pH} \geq 7$ [13]. The adsorption capacity of this nanoclay can change depending on the dispersion conditions, as observed in other nanoclays like montmorillonite. Solvent nature, $\mathrm{pH}$ [14], surface modification with surfactants [15], mordant salts or silane [16] can be used to modify the nanoclay adsorption behavior [17].

Other nanoclay structures have been studied to adsorb and stabilize organic compounds like dyes. Halloysite is a type of hollow tubular nanostructure mineral clay. This nanoclay chemical structure is similar to kaolin, but is rolled into tubes. Because of its tubule shape, halloysite does not stack together and can be easily exfoliated by steering. Halloysite clay is transparent and does not significantly change polymer composites' transparency [18]. Halloysite nanotubes boost the properties of fluorescent dyes by their encapsulation [19]. Functionalized halloysite has been fabricated as a novel hybrid clay mineral for dye removal. This nanoclay can absorb cationic or anionic organic compounds owing to their surface properties, which make it an excellent adsorbent used for the removal of different dyes from wastewater [20].

With halloysite hybrid pigments, nanolevel dispersions of dyes provide polystyrene with enhanced luminescence [21]. The hybrid materials that result from the adsorption of dyes into modified nanoclays have been used to modify optical [22], mechanical, fire or barrier properties of different polymer matrices with successful results, depending on nanoclay particle exfoliation [23-28].

Total solar reflectance (TSR) is the method that measures a surface coating's reflective capability. Urban areas show higher air temperatures than rural areas. The use of the so-called "cool paints" or "cool coating", i.e., with high TSR (\%) values on building surfaces, is a countermeasure to mitigate this urban heat island [29]. In addition, "cool coatings" can decrease the sensitive heat load to the atmosphere and thermal storage in building frames due to solar radiation [30]. $\mathrm{TiO}_{2}$ particles have been employed to increase the TSR of building coatings by functionalized anatase immobilization in an organosiloxane matrix. In addition, nanoclays have displayed protection against UV for coatings [31].

This work utilizes different nanoclay structures, laminar laponite and tubular halloysite, to protect natural chlorophyll. The aims are to: obtain natural sustainable hybrid pigments with improved properties; compare different synthesis conditions with surface modification and $\mathrm{pH}$ levels to improve synthesis performance, measured as natural dye adsorption, and hybrid pigment optical properties as TSR (\%) values.

\section{Materials and Methods}

\subsection{Materials}

Copper chlorophyll (NG) CI.75810 $\left(\mathrm{C}_{34} \mathrm{H}_{31} \mathrm{CuN}_{4} \mathrm{Na}_{3} \mathrm{O}_{6}\right)$, was supplied by Sensient ${ }^{\circledR}$ (Milwaukee, WI, USA). Nanoclays laponite and halloysite were supplied by Southern Clay Products (Gonzales, TX, USA) and Sigma-Aldrich (St. Louis, MO, USA), respectively. To modify nanoclay surfaces, surfactant (SURF) cetylpyridinium bromide $\mathrm{C}_{21} \mathrm{H}_{38} \mathrm{BrN} \cdot 6 \mathrm{H}_{2} \mathrm{O}$, $384.44 \mathrm{~g} / \mathrm{mol}$, mordant salt (MORD) aluminum potassium sulfate dodecahydrate AlK $\left(\mathrm{SO}_{4}\right)_{2} \cdot 12 \mathrm{H}_{2} \mathrm{O}, 474.39 \mathrm{~g} / \mathrm{mol}$, and coupling agent (SIL) (3-Aminopropyl) triethoxysilane $\mathrm{H}_{2} \mathrm{~N}\left(\mathrm{CH}_{2}\right)_{3} \mathrm{Si}\left(\mathrm{OCH}_{3}\right)_{3}, 179.29 \mathrm{~g} / \mathrm{mol}$, were used. To record any changes in $\mathrm{pH}$ during the synthesis process, hydrochloric acid HCL-(37\%) was purchased from Sigma-Aldrich. All these agents were supplied by Sigma-Aldrich. Lastly, for bio-nanocomposite generation, we used the bioresin whose trade name is GreenPoxy 55, which is an epoxy system with a single hardener where $55 \%$ of the molecular structure is of plant origin. Catalyst SD 505 came from SICOMIN Composites (Chateauneuf les Martigues, France). 


\subsection{Synthesis Process}

The adsorption of chlorophyll dye into the laminar nanoclays was performed using water as the solvent and the stirring method. The times to incorporate each modifier were selected according to previous studies [32]. In this study, both nanoclays were dispersed at $1800 \mathrm{rpm}$ for $20 \mathrm{~h}$. Laponite dispersions were prepared at $18 \mathrm{~g} \cdot \mathrm{L}^{-1}$ to avoid gel formation in distilled water. The halloysite nanoclay was heat-treated for $24 \mathrm{~h}$ at $220^{\circ} \mathrm{C}[33,34]$ and dispersed in distilled water at $25 \cdot \mathrm{L}^{-1}$. In both nanoclay dispersions, $\mathrm{pH}$ was adjusted to -4 using $37 \% \mathrm{HCl}[35,36]$. The dye concentration in solutions was $2 \times 10^{-3} \mathrm{M}$. The surface modifiers concentration fell within a range of $0-2 \%$ over the nanoclay mass. Dye exchange was performed by stirring at $1800 \mathrm{rpm}$ and room temperature for $4 \mathrm{~h}$, and then at $600 \mathrm{rpm}$ for $20 \mathrm{~h}$. Solvent separation was carried out by centrifuging to obtain the paste-nano-pigment (PNP). Then the PNP was washed by redispersing its paste at $400 \mathrm{rpm}$ for $30 \mathrm{~min}$ until the supernatant was clear. The complete separated supernatant was collected from the beginning to the final washing step. Measurements were taken for each sample immediately before collecting supernatants to avoid dye degradation. To ensure that all the non-adsorbed dye was recovered, the water and solution from washing were protected from light and temperature in airtight containers covered with aluminum. Then the separated supernatants were made up to a known volume to continue with the spectrometer measurements. Thirteen chlorophyll dilutions from $1 \times 10^{-6}[\mathrm{M}]$ to $1 \times 10^{-4}[\mathrm{M}]$ were prepared to obtain the Lambert Beer line as the spectrophotometer calibration method. Lastly, the PNP was cool-dried by an ALPHA 1-2 LDplus lyophilizer (Martin Christ, Osterode am Harz, Germany) for $24 \mathrm{~h}$ providing the fine green powder that we used for the characterization and the application (Figure 1).

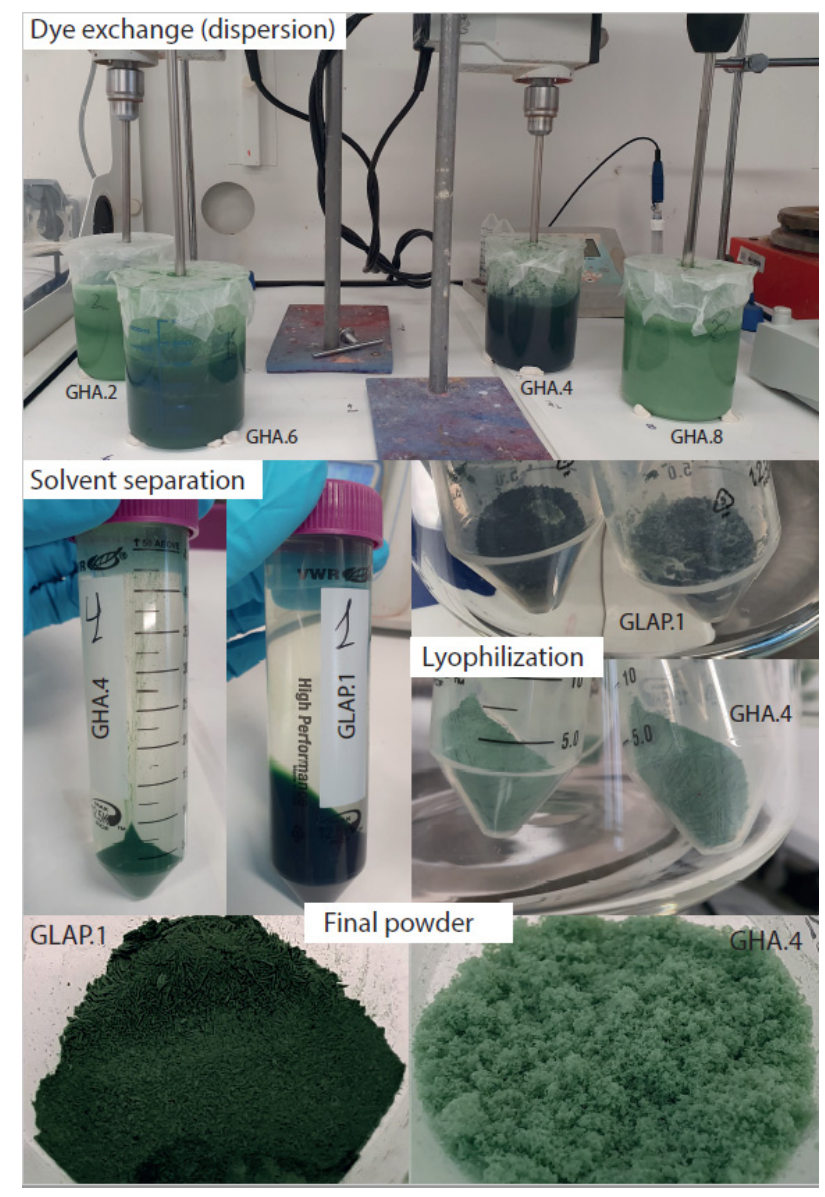

Figure 1. Synthesis steps pictures with halloysite (GHA) and laponite (GLAP) examples. 


\subsection{Biocomposite Generation}

Bio-composite materials were handmade by mixing with the commercially recommended catalyst, and using silicon templates to obtain plain rectangular samples (Figure 2). We employed $10 \%$ over the bio-resin mass nano-pigment concentrations. The curing process was carried out at $90^{\circ} \mathrm{C}$ for $3 \mathrm{~h}$.

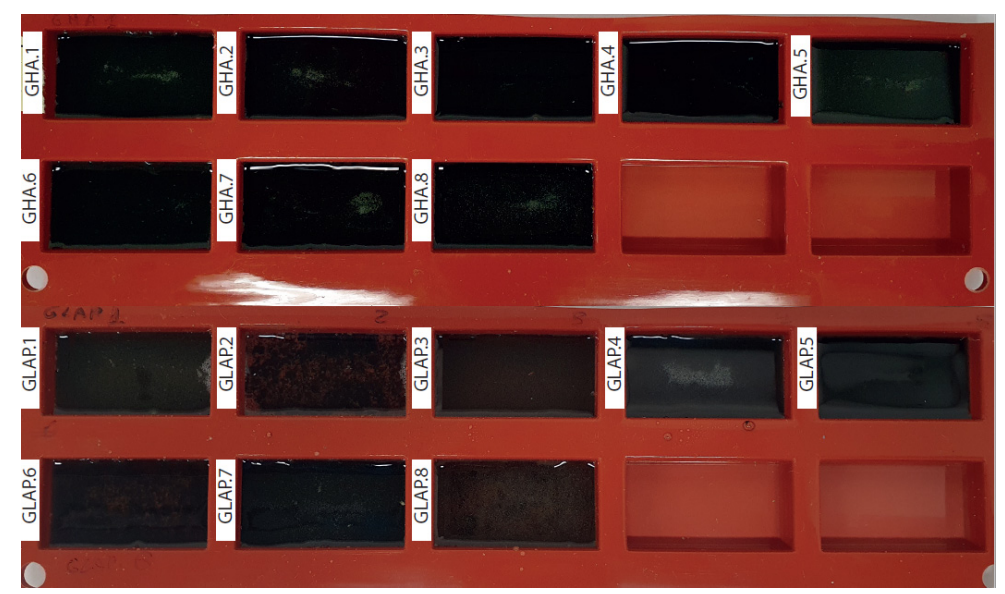

Figure 2. Biocomposite preparation after epoxy 55 curing step with GHA and GLAP hybrid pigment addition at different synthesis conditions.

\subsection{Characterization}

The determination of the amount of dye adsorbed by the nano-clay system allowed us to define the synthesis performance of the process. For this purpose, a UV-Vis transmission spectrophotometer (JASCO V650, Easton, MD, USA) was utilized to measure the dye absorbance $(\%)$ in separate supernatants. Then the amount of dye adsorbed by nanoclays was calculated as a percentage of the initial concentration in the exchange step. This parameter was employed as a response to minimize in the DoE analysis.

XRD Bruker D8-Advance equipment (Bruker, Billerica, MA, USA), with a Göebel mirror (power: $3000 \mathrm{~W}$, voltage: $20-60 \mathrm{kV}$ and current: 5-80 mA), was used. Measurements were taken in an oxidant atmosphere at an angular speed of $1^{\circ} / \mathrm{min}$, STEP $0.05^{\circ}$, and an angular scan of $2.7-70^{\circ}$. XRD patterns were obtained to observe variations in the basal space on the layers from the different nanoclays due to the interactions with the natural dye and modifiers.

For TSR (\%), a double UV-Vis/NIR Jasco V-670 spectrometer was used, which works within the wavelength range from 190 to $2700 \mathrm{~nm}$. The equipment has a double-grating monocromator, one for the UV-Vis region $(1200$ grids $/ \mathrm{mm}$ ) and the other for the NIR region (300 grids $/ \mathrm{mm}$ ). Detectors are a photomultiplier tube for the UV-Vis region and a PbS detector for the NIR region. Both the detector and grating changes are automated at a user-fixed wavelength between 750 and $900 \mathrm{~nm}$. The light sources are a deuterium lamp (190 to $350 \mathrm{~nm}$ ) and a halogen lamp (330 to $2700 \mathrm{~nm}$ ). To calculate optical properties, reflectance factors $\rho(\lambda)$ were applied for the hybrid pigments within the $370-740 \mathrm{~nm}$ range with the D65 illuminant and the CIE-1964 standard [11] observer.

A thermogravimetric analyzer TGA/SDTA 851 (Mettler-Toledo Inc., Columbus, OH, USA) was utilized to ensure that chlorophyll was successfully loaded on both nanoclays. The experimental conditions were a temperature ramp of $5{ }^{\circ} \mathrm{C} / \mathrm{min}$ within the $20-900{ }^{\circ} \mathrm{C}$ range with oxidant medium $\mathrm{N}_{2}: \mathrm{O}_{2}(4: 1)$.

Finally, a SOLARBOX 1500e RH climatic chamber (ERICHSEN, Hemer, Germany) was used to measure the color UV-Vis fastness. All samples were measured using a Konica Minolta sphere integrated spectrophotometer (CM-2600d) to obtain the reflectance factors $\rho(\lambda)(370-740)$ nm range with the D65 illuminant and the CIE-1964 standard observer. The measurements were made at several exposure time intervals, and color differences were calculated by measuring samples before and after radiation exposure. Color differences $\Delta \mathrm{E}_{\mathrm{ab}}{ }^{*}$ were calculated with the colorimetric attributes of the CIELAB color space. 


\subsection{Statistical Design of Experiments}

In order to perform the synthesis process by combining different parameters and to find their contribution to the variance in the results, a fractional design of experiments was followed $2^{4-1}$ (Table 1$)$ with factors: $\mathrm{pH}$ (3-4, or natural), nanoclay surface modifiers addition ( $0-2 \%$ over clay mass) surfactant, mordant or silane, and two experimental laminar (LAP) or tubular (HA) blocs for the nanoclay structure. This design allowed us to study all the simple effects of factors and the $\mathrm{pH}$ modifiers interactions. Synthesis performance, degradation temperature, and total solar reflectance were used as a response to analyze the synthesis factors effects.

Table 1. Synthesis condition analysis using the $2^{4-1}$ DoE experiment and two experimental blocs; 1-laponite, 2-halloysite, and dispersion $\mathrm{pH}$, surfactant (SURF), mordant (MORD), and/or silane (SIL) factors.

\begin{tabular}{ccccc}
\hline Sample Code & $\mathbf{p H}^{\mathbf{1}}$ & SURF $^{\mathbf{2}}$ & MORD $^{\mathbf{2}}$ & SIL $^{\mathbf{2}}$ \\
\hline GLAP.1 & 4 & 0 & 0 & 0 \\
GLAP. & 9 & 0 & 0 & 2 \\
GLAP.3 & 4 & 2 & 0 & 2 \\
GLAP. & 9 & 2 & 0 & 0 \\
GLAP.5 & 4 & 0 & 2 & 2 \\
GLAP.6 & 9 & 0 & 2 & 0 \\
GLAP.7 & 4 & 2 & 2 & 0 \\
GLAP.8 & 9 & 2 & 2 & 2 \\
GHA.1 & 4 & 0 & 0 & 2 \\
GHA.2 & 9 & 0 & 0 & 2 \\
GHA.3 & 4 & 2 & 0 & 0 \\
GHA.4 & 9 & 0 & 2 & 2 \\
GHA.5 & 4 & 0 & 2 & 0 \\
GHA.3 & 9 & 2 & 2 & 2 \\
GHA.3 & 4 & 2 & 2 & 0 \\
GHA.8 & 9 & 2 & 0 & 2 \\
\hline
\end{tabular}

${ }^{1}$ Nanoclay in water dispersion $\mathrm{pH} .{ }^{2}$ Modifier concentration \% over nanoclay mass.

\section{Results and Discussion}

Different characterization analyses were performed to know the structural and optical properties of the different hybrid pigments.

\subsection{Chlorophyll Adsorption}

All the supernatants separated after the centrifugation step were measured to find the presence of natural colorants to calculate synthesis performance as the percentage of dye adsorbed in both nanoclays (Ads(\%)) (Table 2). Significant differences were found depending on the synthesis conditions. The analysis of variance revealed that the significant factors in the percentage of dye adsorbed in both nanoclays (Ads $(\%)$ ) were the mordant and $\mathrm{pH}$ interactions (see Table 3). The p-values in both factors were lower than 0.05 . According to Figure 3, when mordant salt was present $(\mathrm{MORD}=1.0)$, no differences appeared due to the $\mathrm{pH}$ level (from -1.0 to 1.0), and the supernatant was clear and dye adsorption was maximum $(\approx 99 \%)$ in both structures. However, when no mordant salt was present $(\mathrm{MORD}=-1.0), \mathrm{pH}$ became a critical factor and had to be acidic $(\mathrm{pH}=-1.0$ (3-4)) to maintain dye adsorption close to $99 \%$ in both nanoclay structures. The lowest adsorption percentage $(\approx 84 \%)$ was found at a natural $\mathrm{pH}(\mathrm{pH}=1.0(9-7))$ with no mordant salt present $(\mathrm{MORD}=-1.0)$. Based on these results, the mordant-modified solvent ion strengthened and favored the chlorophyll-clay interaction similarly to the textile dying process. In the halloysite structures, the protonation constants increased accordingly to ionic strength, which favored the chlorophyll interactions. At a low $\mathrm{pH}$, halloysite layers were protonated from $\mathrm{pH} 2$ to $\mathrm{pH}$ 6.5, the silicic surface underwent deprotonation, and its lowest possible negative charge was reached at the highest point of the range. Depending on the nanoclay layer, both ionic strength and $\mathrm{pH}$ changed protonation and favored $\mathrm{H}$ - 
bonding. The aluminic layer was protonated up to $\mathrm{pH} 6$ and then its deprotonation process was affected by ionic strength. The presence of $\mathrm{H}^{+}$in the $\mathrm{W}-\mathrm{SiO}-\mathrm{H}$ system did not allow water molecules to interact with the inner halloysite layer. The preferred protonated site in the acidic chemical environment was the aluminic surface, which was slightly stabler than its silicic counterpart. In addition, the formation of $\mathrm{H}^{3} \mathrm{O}^{+}$species on the positively charged silicic layer made the systems in which it was present much stabler than their analogous version on the aluminic layer [36].

Table 2. The absorption (Ads (\%)) results at $\lambda 405.4 \mathrm{~nm}$ and the percentage of dye adsorbed under different synthesis conditions by the $\operatorname{DoE} 2^{4-1}$, calculation.

\begin{tabular}{ccc}
\hline REF & Abs $\boldsymbol{\lambda} \mathbf{( 4 0 5 . 4} \mathbf{n m})$ & Ads $\mathbf{( \% )}$ \\
\hline GLAP.1 & 0.1267876 & 97.91 \\
GLAP. 2 & 0.4166450 & 80.21 \\
GLAP.3 & 0.1168471 & 98.51 \\
GLAP.4 & 0.1445317 & 96.82 \\
GLAP.5 & 0.1220899 & 98.19 \\
GLAP.6 & 0.1101210 & 98.92 \\
GLAP.7 & 0.1197555 & 98.34 \\
GLAP.8 & 0.1242313 & 98.06 \\
GHA.1 & 0.1197628 & 98.34 \\
GHA.2 & 0.2486290 & 90.47 \\
GHA.3 & 0.1279232 & 97.84 \\
GHA.4 & 0.6237080 & 67.57 \\
GHA.5 & 0.1153758 & 98.60 \\
GHA.6 & 0.1140121 & 98.69 \\
GHA.7 & 0.1160737 & 98.56 \\
GHA.8 & 0.1136496 & 98.71 \\
\hline
\end{tabular}

Table 3. Analysis of variance for the percentage of dye adsorbed under different synthesis conditions by DoE $2^{4-1}$.

\begin{tabular}{cccccc}
\hline Source & Sum of Squares & f.d. & Medium Square & F-Ratio & $p$-Value \\
\hline A:pH & 201.863 & 1 & 201.863 & 4.72 & 0.0526 \\
C:MORD & 228.084 & 1 & 228.084 & 5.33 & 0.0414 \\
AC & 211.765 & 1 & 211.765 & 4.95 & 0.0479 \\
Block (nanoclay) & 20.7034 & 1 & 20.7034 & 0.48 & 0.5010 \\
Total Error & 470.507 & 11 & 42.7734 & & \\
Total (corr.) & 1132.92 & 15 & & & \\
\hline
\end{tabular}

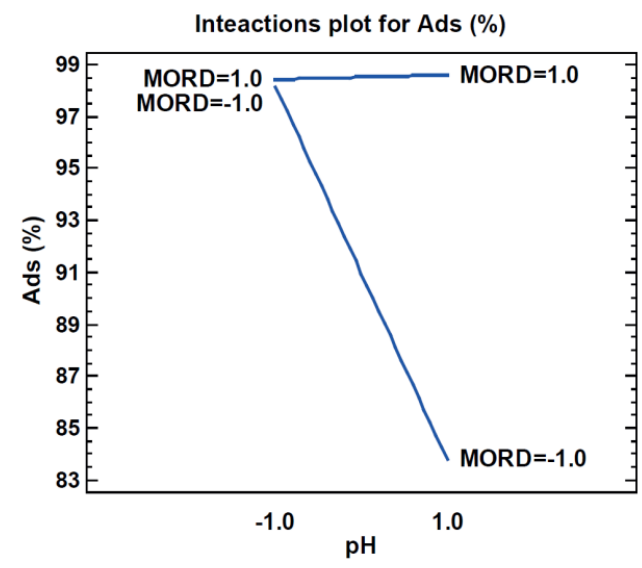

Figure 3. Interactions plot for the synthesis performance as the percentage of dye adsorbed (Ads (\%)) under different conditions with $\mathrm{pH}$ and MORD levels. 


\subsection{UV-VIS-NIR}

We represent the reflectance factors $\rho(\lambda)$ for both nanoclays and hybrid pigments. We observed that both nanoclays reflected more than $60 \%$ NIR radiation from $700-1400 \mathrm{~nm}$, with reflectance decay of $20 \%$. As expected, significant differences appeared when chlorophyll dye $(\mathrm{CP})$ was incorporated into both the nanoclays. In the halloysite hybrids (GHA), NIR reflectance lowered to negative values from $1600-2700 \mathrm{~nm}$, which means radiation absorption. This phenomenon appeared in all the GHA samples, except for the two samples with no surfactant and mordant salt. Another remarkable phenomenon that affected the optical properties and the final TSR\% from both hybrid pigments was VIS reflectance. The laponite hybrid pigments (GLAP) showed less reflectance in UV-VIS, and a close NIR from 700 to $1400 \mathrm{~nm}$, than the GHA samples (Figures 4 and 5).

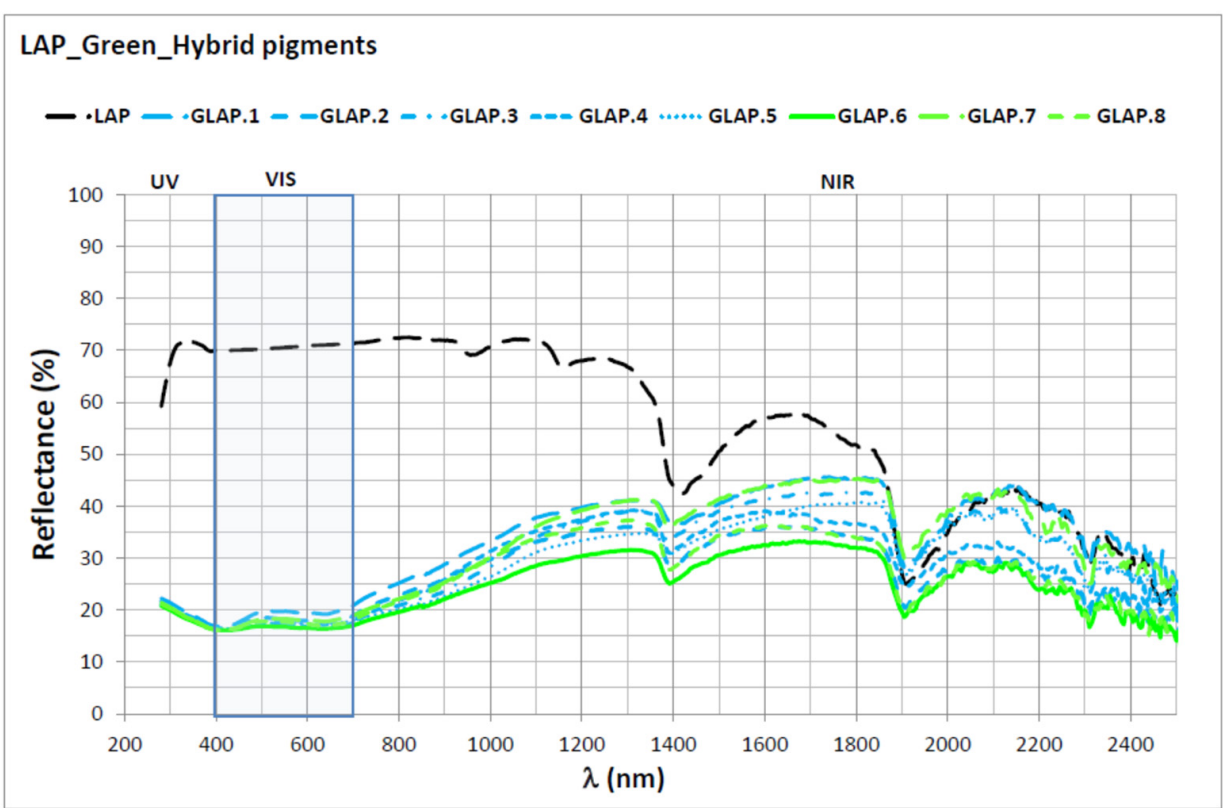

Figure 4. Spectral reflectance UV-VIS-NIR of laponite clay and chlorophyll hybrid pigments GLAP.

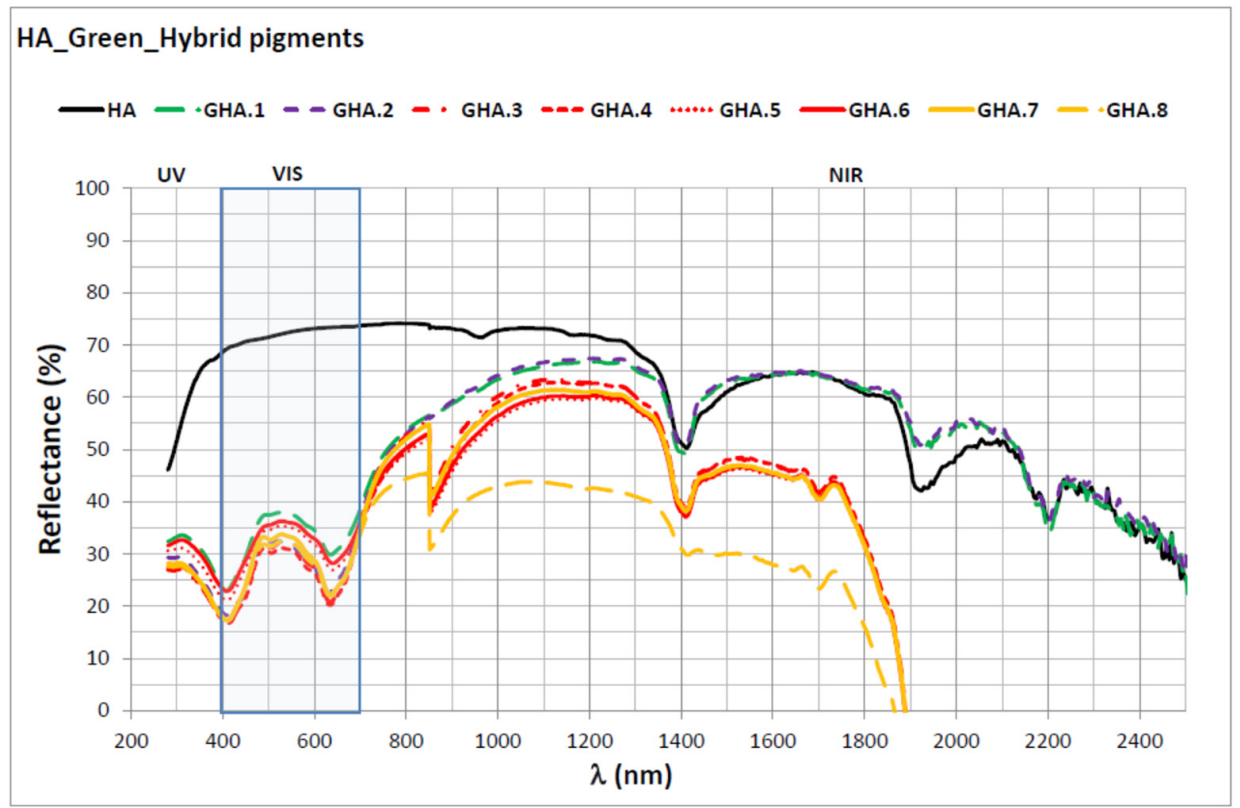

Figure 5. Spectral reflectance UV-VIS-NIR of halloysite clay and chlorophyll hybrid pigments GHA. 


\subsubsection{Total Solar Reflectance \%}

The total solar reflectance calculation requires taking raw reflectance data and applying the solar weighting factors for each collected wavelength. These factors and calculations are included in the respective norms ASTM G173-03 [37]. The total solar reflectance coefficient TSR (\%) calculation subtraction (1 - TSR) corresponds to the degree of total solar absorption of the nanoclay/hybrid pigment. Figure 6 depicts how there were no significant differences between the TSR of the original nanoclays. However, the hybrid pigments from halloysite had higher TSR values than the hybrid pigments from laponite.

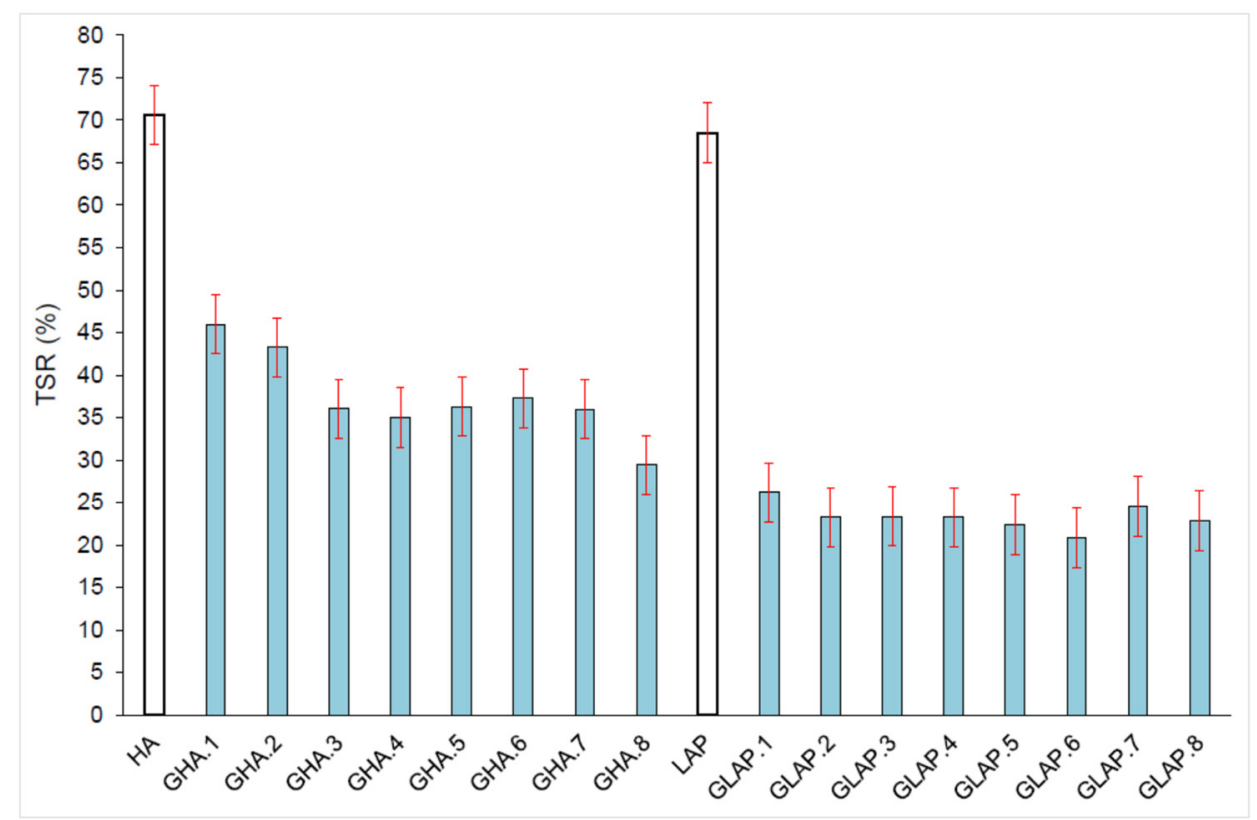

Figure 6. TSR (\%) values from halloysite (HA), laponite (LAP), and chlorophyll hybrid pigments GLAP (1-8) and GHA (1-8).

In addition, differences appeared between the synthesis factors using TSR (\%) as a response to maximize. According to the ANOVA analysis, to maximize the TSR values the optimal levels were obtained for the halloysite nanoclay with no surfactant and mordant, and neither $\mathrm{pH}$ nor the silane modifier factors had any influence (Figure 7). However, significant interactions took place. No influence was noted for the laponite clay in the presence of the surfactant, while halloysite obtained the highest results without this modifier.

At an acidic $\mathrm{pH}$, the presence of silane had a significant influence because the TSR of the hybrid pigments abruptly lowered. However at a natural $\mathrm{pH}$, the effect of silane-treated nanoclay was the exact opposite because the TSR values of the hybrid pigments increased (Figure 8). The functional role of the chemical silane treatment on the hydrophilic halloysite surface contributed with rearranged and delaminated HNT particles, which improved their exfoliation in the polymer matrix and could reflect solar radiation [38]. For instance, we found that this effect in the interaction analysis depended on the $\mathrm{pH}$ level, which also affected the nanoclay sheets arrangement. 

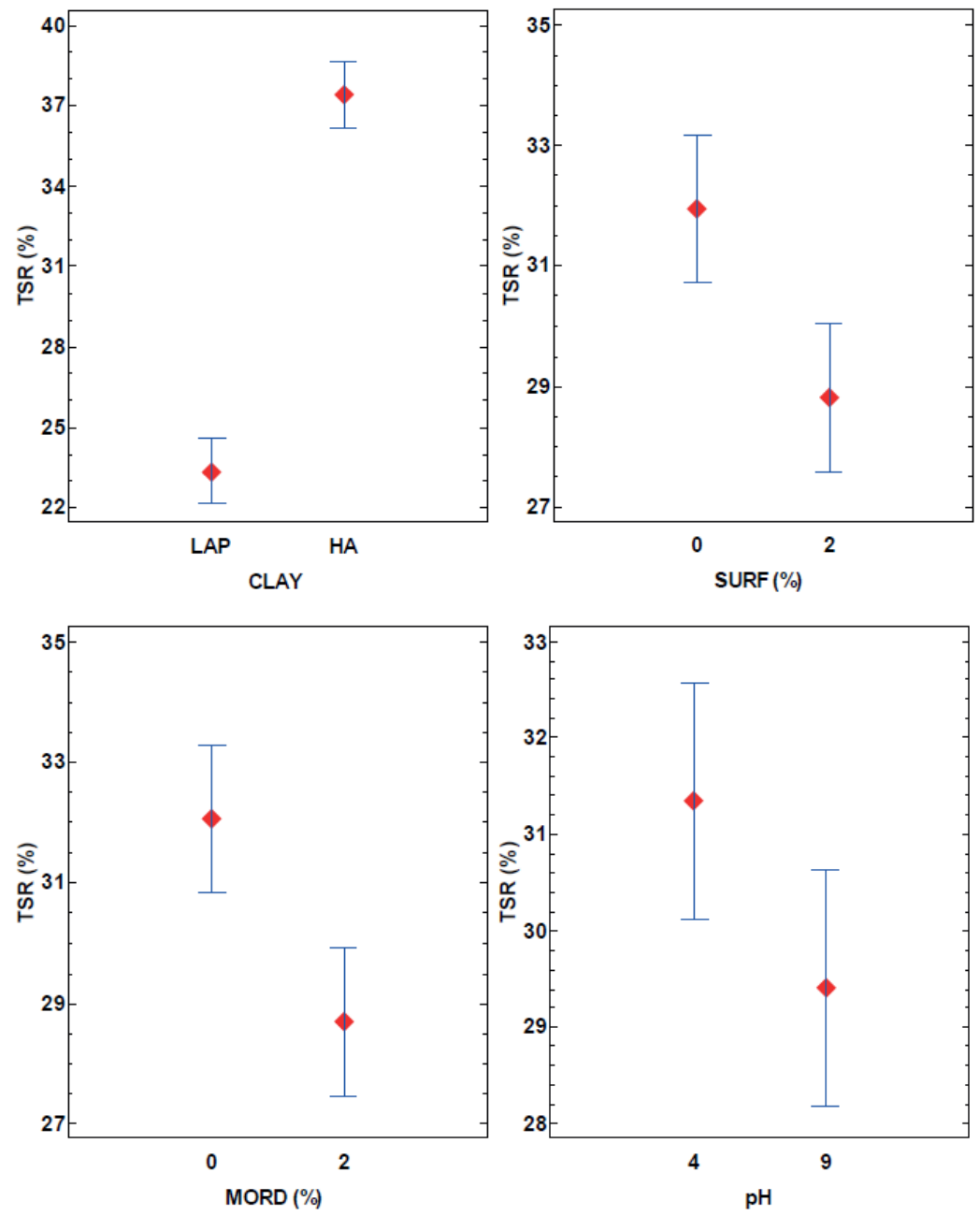

Figure 7. Mean plots of the LSD 95\% confidence intervals from the TSR (\%) response analysis.
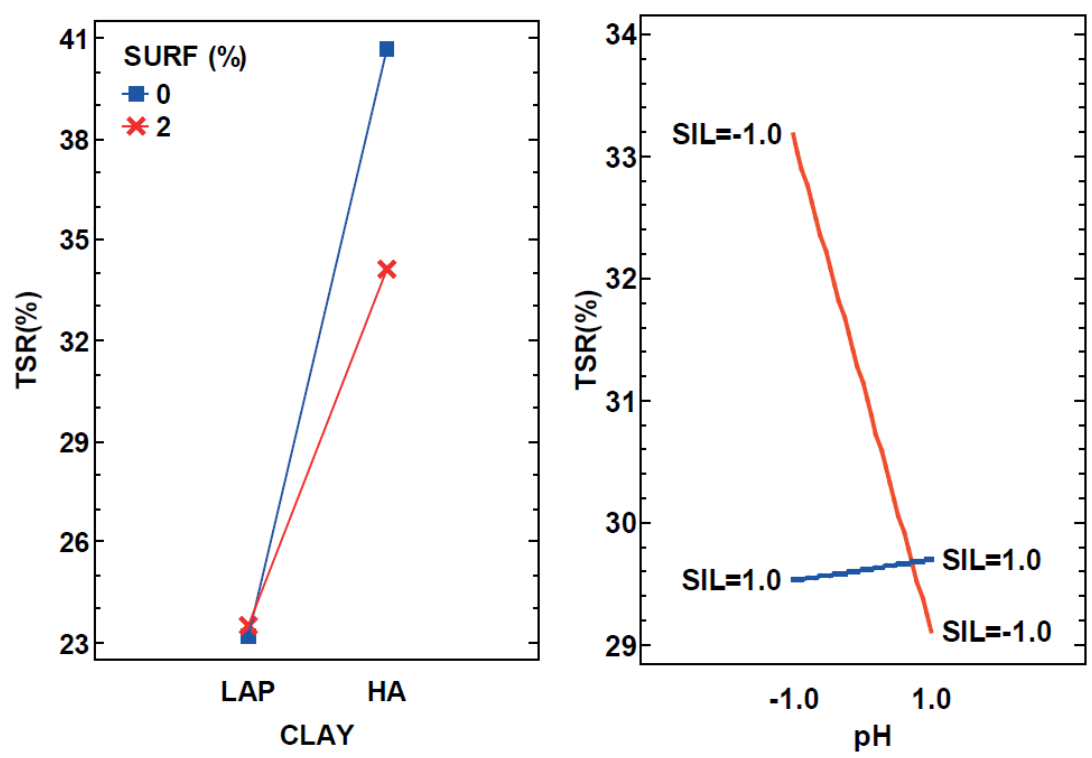

Figure 8. Interactions plot for TSR (\%) with the $\mathrm{pH}$ and CLAY factors. 


\subsubsection{Chromatic Diagrams}

Once the spectral analysis of all samples was carried out, a direct comparison of all the hybrid pigments at the colorimetric level was made. For the colorimetric calculations of each hybrid pigment or clay, the main CIE 15:2004 standard [39] guidelines of the International Commission on Illumination and Color (CIE) were followed to make the absolute and relative colorimetric comparisons. The colorimetric CIELAB parameters codified by the CIE 1931 xyz patron and D65 standard illumination were used. The CIE $a^{*} b^{*}$ and CIE- $C_{a b}{ }^{*} L^{*}$ diagrams in Figure 9 showed significant differences according to the nanoclay and the synthesis process. The GHA pigments became greenish and yellowish samples. The chroma $\left(C^{\mathrm{ab} *}\right)$ and lightness $\mathrm{L}^{*}$ attributes were also higher in the GHA samples. The DoE analysis showed that more chromatic samples were found in the presence of the surfactant, but the main difference in that parameter was due to the nanoclay (Table 4) (Figure 10). Darker samples were obtained with the laponite nanoclays when the surfactant was present and at a natural pH (Table 5) (Figure 11).

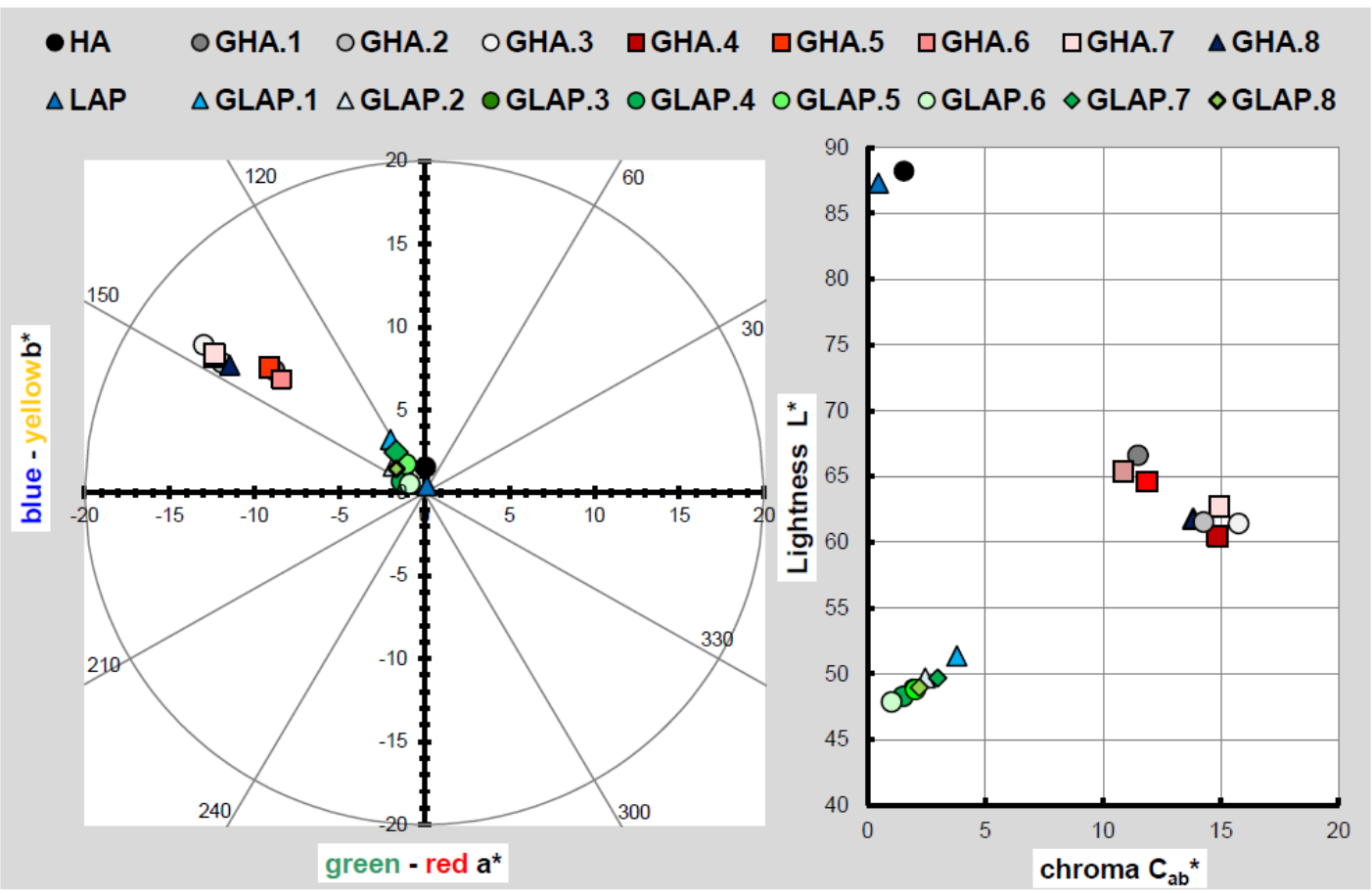

Figure 9. Graphic CIELAB plots for laponite (LAP), halloysite (HA) and the hybrid pigments with chlorophyll, GLAP and GHA using the D65 illuminant and the CIE-1931 XYZ standard observer. Left: CIE-a* b* color diagram; right: CIE-Cab* L* color chart.

Table 4. Analysis of variance for $C_{a b}{ }^{*}$ values for the different synthesis conditions by DoE $2^{4-1}$.

\begin{tabular}{cccccc}
\hline Source & Sum of Squares & f.d. & Medium Square & F-Ratio & $p$-Value \\
\hline B:SURF & 6.50922 & 1 & 6.50922 & 4.26 & 0.0562 \\
C:MORD & 2.5302 & 1 & 2.5302 & 1.62 & 0.2297 \\
AD & 2.30904 & 1 & 2.30904 & 1.48 & 0.2499 \\
Block (nanoclay) & 505.654 & 1 & 505.654 & 323.14 & 0.0000 \\
Total Error & 17.2128 & 11 & 1.5648 & & \\
Total (corr.) & 534.215 & 15 & & & \\
\hline
\end{tabular}



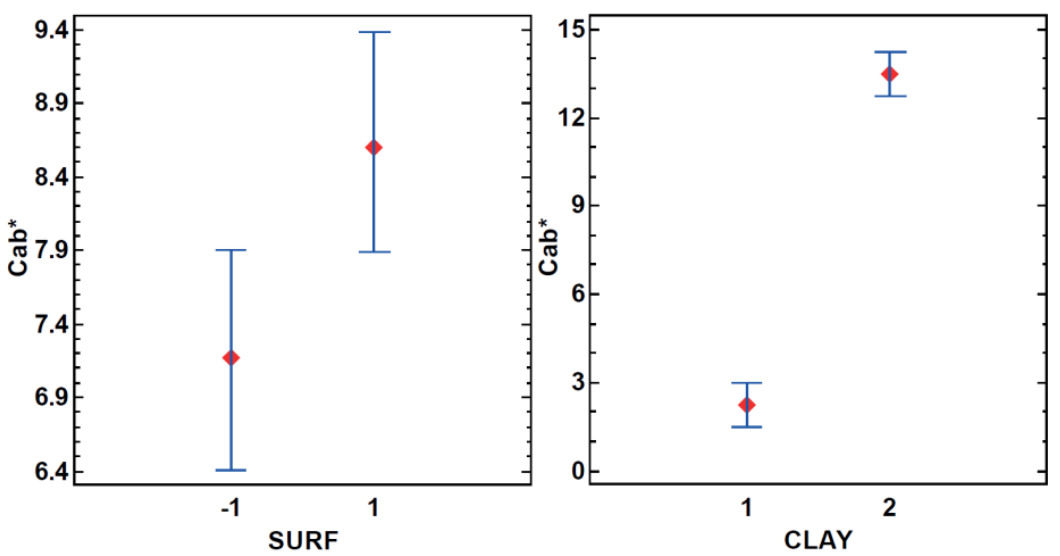

Figure 10. The LSD median plots for the SURF and CLAY factors with the $\mathrm{C}_{\mathrm{ab}}{ }^{*}$ response.

Table 5. Analysis of variance for $L^{*}$ values for the different synthesis conditions by DoE $2^{4-1}$.

\begin{tabular}{cccccc}
\hline Source & Sum of Squares & f.d. & Medium Square & F-Ratio & $p$-Value \\
\hline A:pH & 6.40622 & 1 & 6.40622 & 3.34 & 0.0950 \\
B:SURF & 11.6339 & 1 & 11.6339 & 6.06 & 0.0316 \\
D:SIL & 2.74599 & 1 & 2.74599 & 1.43 & 0.2569 \\
Block (nanoclay) & 769.524 & 1 & 769.524 & 400.68 & 0.0000 \\
Total Error & 21.1259 & 11 & 1.92053 & & \\
Total (corr.) & 811.436 & 15 & & & \\
\hline
\end{tabular}
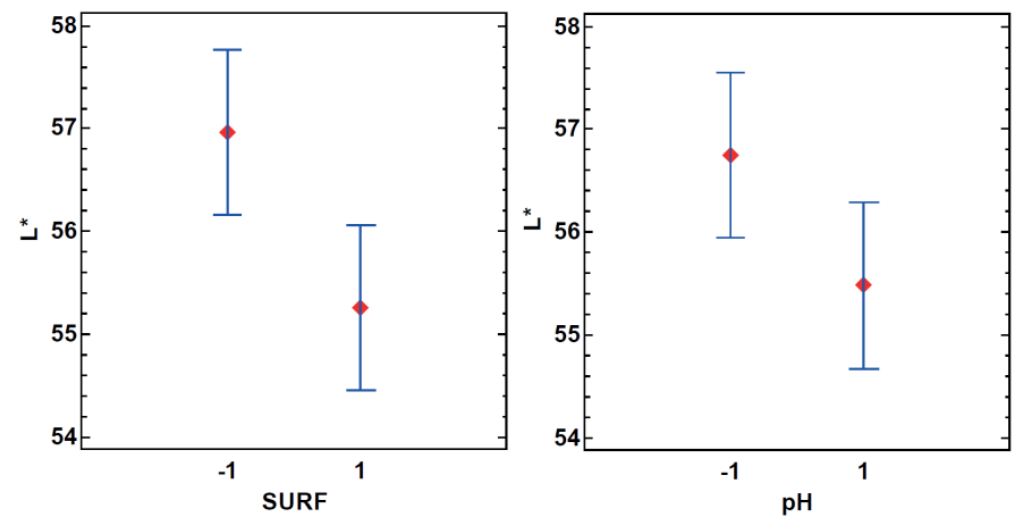

Figure 11. The LSD median plots for the SURF and CLAY factors with the L* response.

\subsection{XRD}

The XRD pattern of the halloysite and GHA hybrids exhibited the characteristic peaks at $2 \theta=8^{\circ}, 13^{\circ}, 22.8^{\circ}, 28^{\circ}, 31^{\circ}, 58^{\circ}$, and $67^{\circ}[40,41]$. In these samples, the first halloysite peak appeared at $11.5^{\circ}$, with an increase to $12.3^{\circ}$ in all the GHA samples. This increase corresponded to an effect on the displacement of the $\mathrm{d}_{001}$ peaks, which indicates a short distance from $0.756 \mathrm{~nm}$ in the original nanoclay to $0.730 \mathrm{~nm}$ (GHA samples). The organic load onto the nanoclay structure under all the synthesis conditions resulted in clay layer compression, with no significant differences in the selected factors (Figure 12).

Therefore, as previously mentioned before, it was clear that the surface modification of laponite with hydrophobic groups greatly enhanced the intercalation of bulky hydrophobic molecules in laponite [16]. In Figure 11, the XRD patterns show the displacement of the $\mathrm{d}_{001}$ peaks over a longer distance, from $1.41 \mathrm{~nm}$ in the original nanoclay to $1.46-1.54 \mathrm{~nm}$, depending on the synthesis conditions. However, no significant statistical differences were found due to the factor level changes. The displacement of laponite sheets was due to the organic compounds adsorption between the laponite basal spaces (Figure 13). 


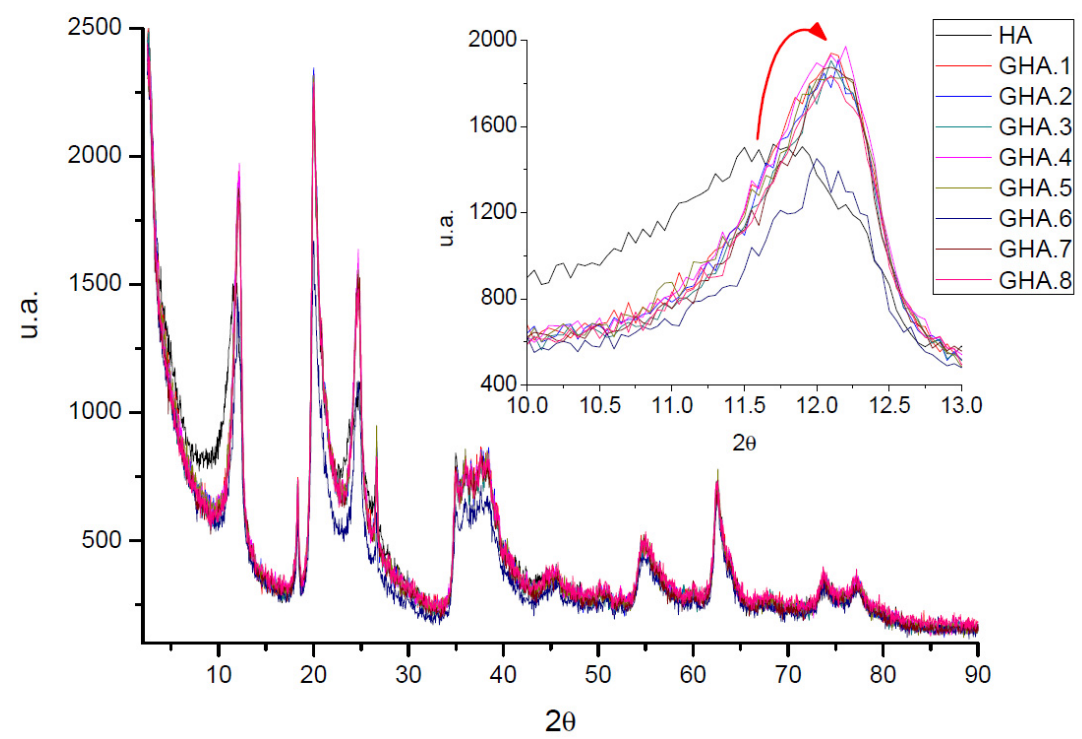

Figure 12. XRD patterns for the halloysite (HA), and the chlorophyll hybrid pigments [GHA.1_8].

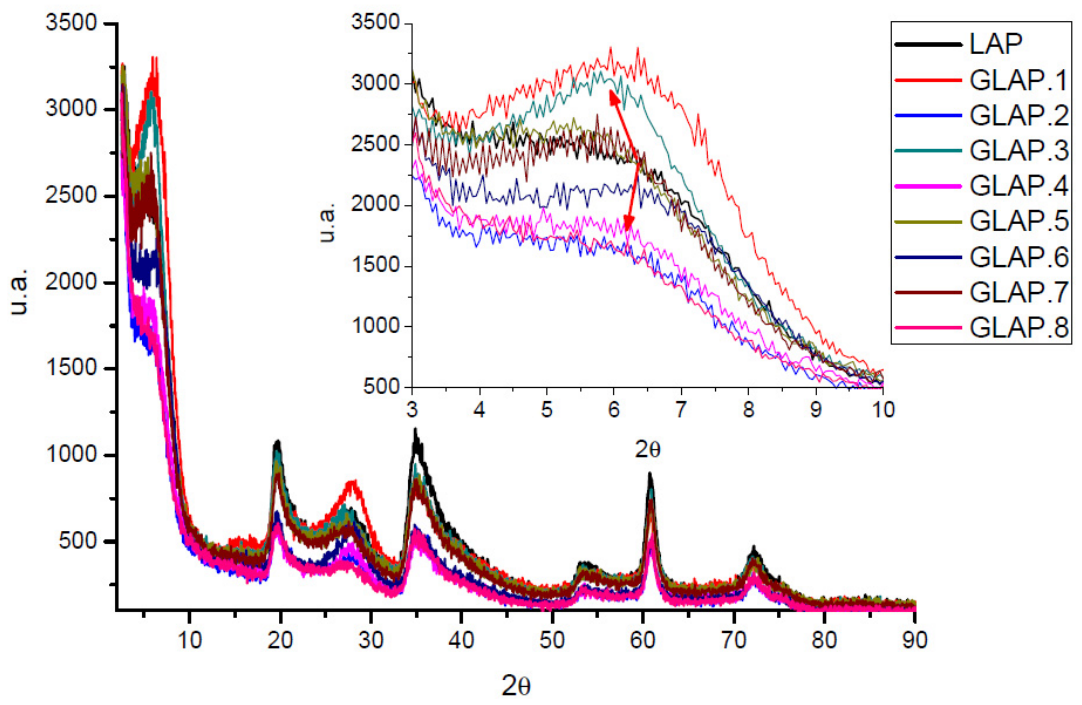

Figure 13. XRD patterns for the laponite (LAP), and the chlorophyll hybrid pigments [GLAP.1_8].

\subsection{Thermal Analysis DTA}

The thermograms of the original nanoclays and the GHAL or GLAP hybrid pigments were performed. In the laponite hybrid pigments, it was difficult to find peaks for the temperature degradation of the chlorophyll dye due to noise and the strongest nanoclay effect. It was only possible to see the reduced $\mathrm{H}_{2} \mathrm{O}$ desorption in the hybrid pigments due to water substitution occurring during the synthesis process. The same occurred with the halloysite hybrids (Figure 14). According to the literature [42,43], the two weight losses observed for halloysite could be due to loss of $\mathrm{H}_{2} \mathrm{O}$ and halloysite matrix dehydroxylation. The first peak assigned to $\mathrm{H}_{2} \mathrm{O}$ loss before $100^{\circ} \mathrm{C}$ significantly decreased for all GHA hybrid samples [1_8]. DTA showed a mild endothermic and marked exothermic behavior at $100^{\circ} \mathrm{C}$ and $300{ }^{\circ} \mathrm{C}$, respectively, which is consistent with the TGA data, and showed the physical desorption of the sample's adsorbed water at $100{ }^{\circ} \mathrm{C}$ and the oxidative desorption of organic compounds (chlorophyll, surfactant and silane) between $300-400{ }^{\circ} \mathrm{C}$ [44]. Therefore, all the hybrid samples displayed good thermal stability up to $300^{\circ} \mathrm{C}$. This analysis confirmed the formation of one phase because only one exothermic step was shown for the GHA samples (Figure 15). 


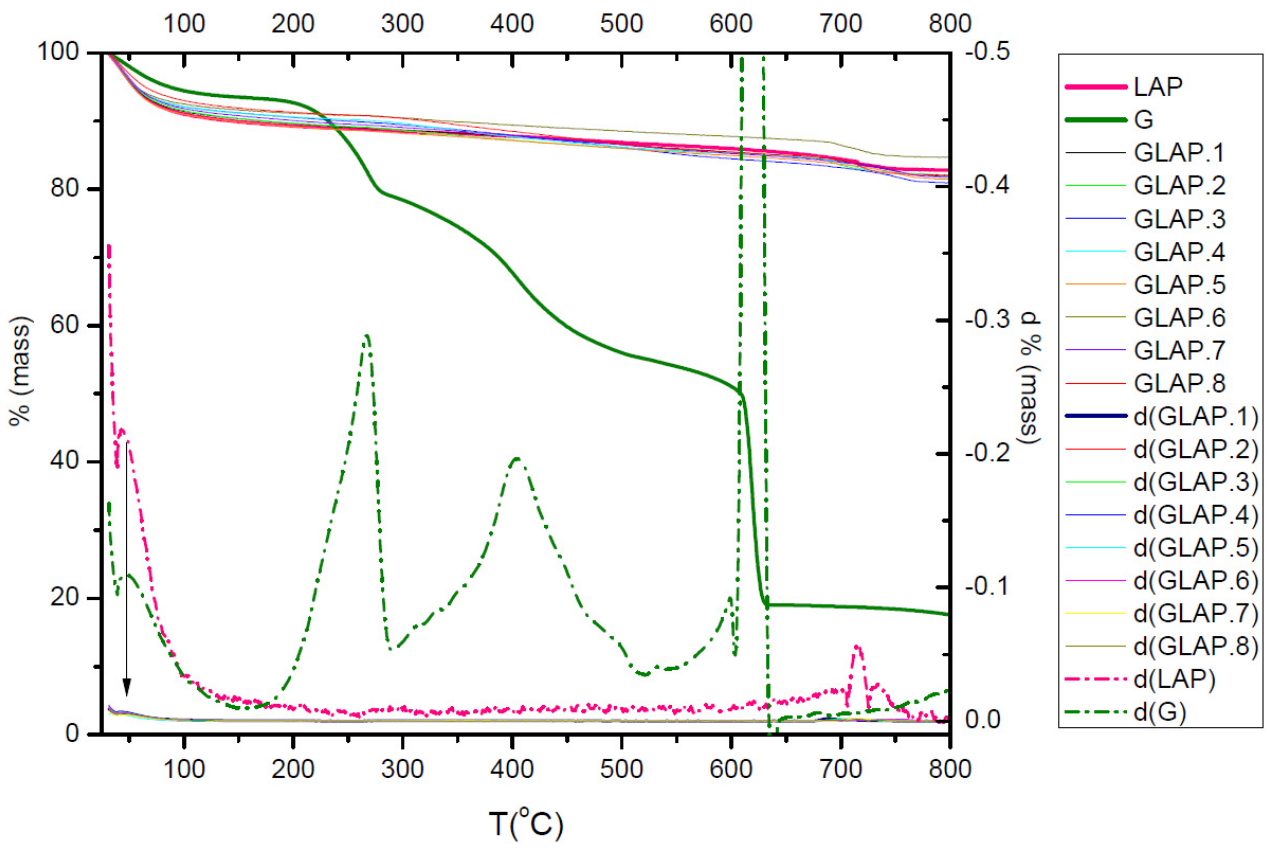

Figure 14. TGA-DTA diagram of laponite (LAP), chlorophyll (G) and the synthesized hybrid pigments GHA for the different conditions [1_8].

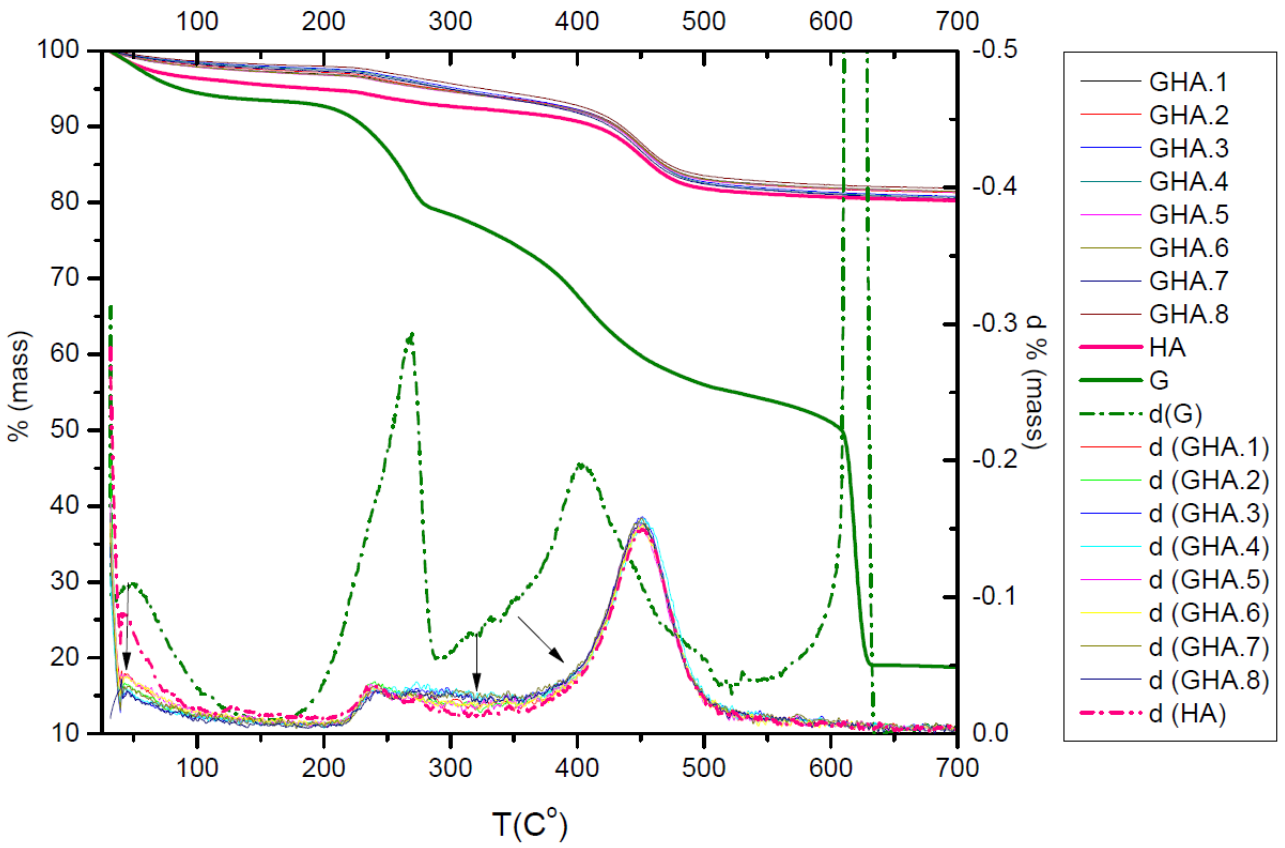

Figure 15. TGA-DTA diagram of halloysite (HA), chlorophyll (G) and the synthesized hybrid pigments GHA for the different conditions [1_8].

\subsection{Colour Fastness}

The aging test was controlled by taking color measurements from $\mathrm{t} 0$ (initial) using the samples with the $10 \%$ hybrid pigment or the original dyes, to $102 \mathrm{~h}$, which corresponds to three months with real sun exposure. Previous works have checked organic dye stabilization in nanoclay structures by changes in absorption curves [45]. We calculated the color difference $\left(\triangle \mathrm{Eab}^{*}\right)$, and standardized the calculated values by natural dye content $(\mathrm{g})$ in each sample $\left(\Delta \mathrm{Eab}^{*} /\right.$ g.dye). Standard errors were also calculated and represented to make comparisons. Figure 16 shows, the color UV-Vis fastness of chlorophyll natural 
dye increased when used as hybrid pigment with both nano-clays. The color differences calculated as $\Delta \mathrm{Eab}^{*}$ (g.col) were significantly bigger for the sample with the original natural dye. For $22 \mathrm{~h}$, the color differences of the samples with the original dye was bigger than $4 \Delta \mathrm{Eab}^{*}$ units, which corresponds to a marked visible change for the human eye, meanwhile the hybrid samples keep the color differences under $1 \Delta \mathrm{Eab}^{*}$ units (Figure 16). It is also remarkable that the color differences that we could observe in the biocomposites with both nanoclays were yellowish due to the epoxy resin degradation. However, in the sample generated with the natural chlorophyll the color difference corresponds to a significant dye degradation with lighter appearance.

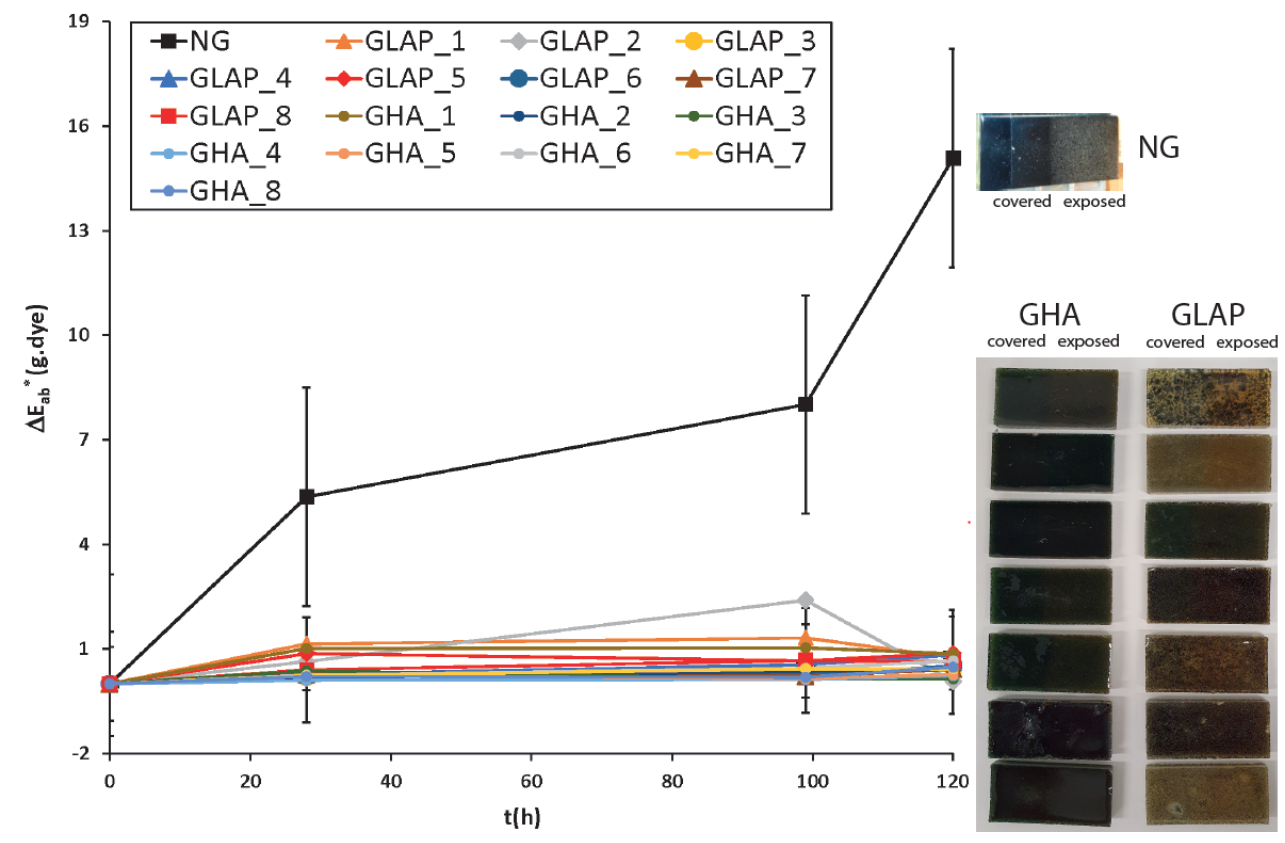

Figure 16. TGA-DTA diagram of halloysite (HA), chlorophyll (G) and the synthesized hybrid pigments GHA for the different conditions [1_8].

\section{Conclusions}

In the present study, the adsorption of copper chlorophyll in two types of nanoclay structures, halloysite nanotubes and laponite sheets, was successfully achieved, which was found in the XRD pattern modifications and the DTA thermal analysis. By using DoE, we found interactions in different synthesis factors, which affected the final hybrid pigments. First, adsorption behavior was affected by $\mathrm{pH}$ and ionic strength from adding mordant salt. Maximum dye adsorption took place at an acidic $\mathrm{pH}$ with or without mordant salt, or at a natural $\mathrm{pH}$ in water dispersion when mordant salt was added. Optical properties were also affected by the modifiers during synthesis. TST (\%) improved without silane under acidic conditions or with silane at natural $\mathrm{pH}$. The halloysite hybrid pigments obtained higher TSR(\%) values with no surfactant.

Color perceptions were affected, and darker samples were obtained with the laponite sample, the surfactant and at a natural $\mathrm{pH}$, while the Chroma $\mathrm{C}_{\mathrm{ab}}{ }^{*}$ value increased. The highest values were obtained with the surfactant and halloysite samples. These new hybrid halloysite/laponite pigments can be optimized following the results of the DoE analysis to be used for different industrial applications, such as thermoplastic polymers for 3D printing filaments, packaging, coatings, inks, etc., and by putting to good use a wide natural color range and improved TSR (\%) properties.

The color fastens was also improved in the biocomposites application. The samples generated with $10 \%$ of hybrid pigments (from HA or LAP clay), show higher colorfastness than the sample with the natural chlorophyll, due to the nanoclays-dye interaction and protection. 
Author Contributions: Writing—original draft preparation, B.M.-V.; methodology, J.J.-N. and B.M.-V.; software, J.J.-N. and B.M.-V.; validation, E.P.R. and V.V.; formal analysis, J.J.-N. and B.M.-V.; investigation, J.J.-N. and B.M.-V.; resources, E.P.R. and V.V.; data curation, B.M.-V. and J.J.-N.; writing-review and editing, E.P.R. and V.V.; supervision, E.P.R. and V.V.; project administration, V.V., funding acquisition, V.V. All authors have read and agreed to the published version of the manuscript.

Funding: This research was funded by Spanish Ministry of Economy and Competitiveness (project RTI2018-096000-B-100).

Institutional Review Board Statement: Not applicable.

Informed Consent Statement: Not applicable.

Acknowledgments: To the Spanish Ministry of Economy and Competitiveness for funding the project entitled: “Diseño y caracterización de la apariencia visual de productos" (REF: RTI2018096000-B-100).

Conflicts of Interest: The authors declare no conflict of interest.

\section{References}

1. Kuo, L.; Chang, B.-G. The Affecting Factors of Circular Economy Information and Its Impact on Corporate Economic SustainabilityEvidence from China. Sustain. Prod. Consum. 2021, 27, 986-997. [CrossRef]

2. Bechtold, T.; Mussak, R. Handbook of Natural Colorants; John Wiley \& Sons: Hoboken, NJ, USA, 2009.

3. Micó-Vicent, B.; Viqueira, V.; Ramos, M.; Luzi, F.; Dominici, F.; Torre, L.; Jiménez, A.; Puglia, D.; Garrigós, M.C. Effect of Lemon Waste Natural Dye and Essential Oil Loaded into Laminar Nanoclays on Thermomechanical and Color Properties of Polyester Based Bionanocomposites. Polymers 2020, 12, 1451. [CrossRef] [PubMed]

4. Shalini, S.; Prasanna, S.; Mallick, T.K.; Senthilarasu, S. Review on Natural Dye Sensitized Solar Cells: Operation, Materials and Methods. Renew. Sustain. Energy Rev. 2015, 51, 1306-1325. [CrossRef]

5. Heinonen, J.; Farahmandazad, H.; Vuorinen, A.; Kallio, H.; Yang, B.; Sainio, T. Extraction and Purification of Anthocyanins from Purple-Fleshed Potato. Food Bioprod. Process. 2016, 99, 136-146. [CrossRef]

6. Keppler, K.; Humpf, H.-U. Metabolism of Anthocyanins and Their Phenolic Degradation Products by the Intestinal Microflora. Bioorg. Med. Chem. 2005, 13, 5195-5205. [CrossRef] [PubMed]

7. Taniguchi, M.; Lindsey, J.S. Synthetic Chlorins, Possible Surrogates for Chlorophylls, Prepared by Derivatization of Porphyrins. Chem. Rev. 2017, 117, 344-535. [CrossRef]

8. Mandal, R.; Dutta, G. From Photosynthesis to Biosensing: Chlorophyll Proves to Be a Versatile Molecule. Sens. Int. 2020, 1, 100058. [CrossRef]

9. Dhafina, W.A.; Daud, M.Z.; Salleh, H. The Sensitization Effect of Anthocyanin and Chlorophyll Dyes on Optical and Photovoltaic Properties of Zinc Oxide Based Dye-Sensitized Solar Cells. Optik 2019, 207, 163808. [CrossRef]

10. Nan, H.; Shen, H.-P.; Wang, G.; Xie, S.-D.; Yang, G.-J.; Lin, H. Studies on the Optical and Photoelectric Properties of Anthocyanin and Chlorophyll as Natural Co-Sensitizers in Dye Sensitized Solar Cell. Opt. Mater. 2017, 73, 172-178. [CrossRef]

11. Di Natale, C.; Monti, D.; Paolesse, R. Chemical Sensitivity of Porphyrin Assemblies. Mater. Today 2010, 13, 46-52. [CrossRef]

12. Au, P.-I.; Hassan, S.; Liu, J.; Leong, Y.-K. Behaviour of LAPONITE ${ }^{\circledR}$ Gels: Rheology, Ageing, PH Effect and Phase State in the Presence of Dispersant. Chem. Eng. Res. Des. 2015, 101, 65-73. [CrossRef]

13. Coelho Leandro, G.; Capello, C.; Luiza Koop, B.; Garcez, J.; Rodrigues Monteiro, A.; Ayala Valencia, G. Adsorption-Desorption of Anthocyanins from Jambolan (Syzygium Cumini) Fruit in Laponite ${ }^{\circledR}$ Platelets: Kinetic Models, Physicochemical Characterization, and Functional Properties of Biohybrids. Food Res. Int. 2021, 140, 109903. [CrossRef] [PubMed]

14. Charaabi, S.; Tchara, L.; Marminon, C.; Bouaziz, Z.; Holtzinger, G.; Pensé-Lhéritier, A.-M.; Le Borgne, M.; Issa, S. A Comparative Adsorption Study of Benzophenone-3 onto Synthesized Lipophilic Organosilicate, Laponite and Montmorillonite. Appl. Clay Sci. 2019, 170, 114-124. [CrossRef]

15. Salleres, S.; López Arbeloa, F.; Martínez, V.; Corcóstegui, C.; López Arbeloa, I. Effect of Surfactant C12TMA Molecules on the Self-Association of R6G Dye in Thin Films of Laponite Clay. Mater. Chem. Phys. 2009, 116, 550-556. [CrossRef]

16. Park, M.; Shim, I.-K.; Jung, E.-Y.; Choy, J.-H. Modification of External Surface of Laponite by Silane Grafting. J. Phys. Chem. Solids 2004, 65, 499-501. [CrossRef]

17. Kausar, A.; Iqbal, M.; Javed, A.; Aftab, K.; Nazli, Z.-H.; Bhatti, H.N.; Nouren, S. Dyes Adsorption Using Clay and Modified Clay: A Review. J. Mol. Liq. 2018, 256, 395-407. [CrossRef]

18. Micó-Vicent, B.; Martínez-Verdú, F.M.; Novikov, A.; Stavitskaya, A.; Vinokurov, V.; Rozhina, E.; Fakhrullin, R.; Yendluri, R.; Lvov, Y. Stabilized Dye-Pigment Formulations with Platy and Tubular Nanoclays. Adv. Funct. Mater. 2018, 28, 1703553. [CrossRef]

19. Riela, S.; Barattucci, A.; Barreca, D.; Campagna, S.; Cavallaro, G.; Lazzara, G.; Massaro, M.; Pizzolanti, G.; Salerno, T.M.G.; Bonaccorsi, P.; et al. Boosting the Properties of a Fluorescent Dye by Encapsulation into Halloysite Nanotubes. Dyes Pigments 2021, 187, 109094. [CrossRef] 
20. Kanani-Jazi, M.H.; Akbari, S. Amino-Dendritic and Carboxyl Functionalized Halloysite Nanotubes for Highly Efficient Removal of Cationic and Anionic Dyes: Kinetic, Isotherm, and Thermodynamic Studies. J. Environ. Chem. Eng. 2021, 9, 105214. [CrossRef]

21. Alam, Q.; Bartczak, P.; Paananen, H.; Suvanto, M.; Pakkanen, T.T. Modification of Halloysite Nanotubes with Xanthene Dyes and Their Application in Luminescent Polymer Nanocomposites. J. Lumin. 2020, 221, 117096. [CrossRef]

22. Marchante Rodríguez, V.; Martínez-Verdú, F.M.; Beltrán Rico, M.I.; Marcilla Gomis, A. Mechanical, Thermal and Colorimetric Properties of LLDPE Coloured with a Blue Nanopigment and Conventional Blue Pigments. Pigment Resin Technol. 2012, 41, 263-269. [CrossRef]

23. Raha, S.; Ivanov, I.; Quazi, N.H.; Bhattacharya, S.N. Photo-Stability of Rhodamine-B/Montmorillonite Nanopigments in Polypropylene Matrix. Appl. Clay Sci. 2009, 42, 661-666. [CrossRef]

24. Bee, S.L.; Abdullah, M.A.A.; Bee, S.T.; Sin, L.T.; Rahmat, A.R. Polymer Nanocomposites Based on Silylated-Montmorillonite: A Review. Prog. Polym. Sci. 2018, 85, 57-82. [CrossRef]

25. Tornuk, F.; Sagdic, O.; Hancer, M.; Yetim, H. Development of LLDPE Based Active Nanocomposite Films with Nanoclays Impregnated with Volatile Compounds. Food Res. Int. 2018, 107, 337-345. [CrossRef] [PubMed]

26. Park, H.-M.; Lee, W.-K.; Park, C.-Y.; Cho, W.-J.; Ha, C.-S. Environmentally Friendly Polymer Hybrids Part I Mechanical, Thermal, and Barrier Properties of Thermoplastic Starch/Clay Nanocomposites. J. Mater. Sci. 2003, 38, 909-915. [CrossRef]

27. Porter, D.; Metcalfe, E.; Thomas, M.J.K. Nanocomposite Fire Retardants-A Review. Fire Mater. 2000, 24, 45-52. [CrossRef]

28. Acharya, H.; Srivastava, S.K.; Bhowmick, A.K. Synthesis of Partially Exfoliated EPDM/LDH Nanocomposites by Solution Intercalation: Structural Characterization and Properties. Compos. Sci. Technol. 2007, 67, 2807-2816. [CrossRef]

29. Krarti, M. Integrated Design of Energy Efficient Cities. In Optimal Design and Retrofit of Energy Efficient Buildings, Communities, and Urban Centers; Butterworth-Heinemann: Oxford, UK, 2018. [CrossRef]

30. Santamouris, M. Cooling the Cities-A Review of Reflective and Green Roof Mitigation Technologies to Fight Heat Island and Improve Comfort in Urban Environments. Sol. Energy 2014, 103, 682-703. [CrossRef]

31. Maharjan, S.; Liao, K.S.; Wang, A.J.; Curran, S.A. Highly Effective Hydrophobic Solar Reflective Coating for Building Materials: Increasing Total Solar Reflectance via Functionalized Anatase Immobilization in an Organosiloxane Matrix. Constr. Build. Mater. 2020, 243, 118189. [CrossRef]

32. Micó-Vicent, B.; Jordán, J.; Perales, E.; Martínez-Verdú, F.; Cases, F. Finding the Additives Incorporation Moment in Hybrid Natural Pigments Synthesis to Improve Bioresin Properties. Coatings 2019, 9, 34. [CrossRef]

33. Asgar, H.; Jin, J.; Miller, J.; Kuzmenko, I.; Gadikota, G. Contrasting Thermally-Induced Structural and Microstructural Evolution of Alumino-Silicates with Tubular and Planar Arrangements: Case Study of Halloysite and Kaolinite. Colloids Surf. A Physicochem. Eng. Asp. 2021, 613, 126106. [CrossRef]

34. Krasilin, A.A.; Danilovich, D.P.; Yudina, E.B.; Bruyere, S.; Ghanbaja, J.; Ivanov, V.K. Crystal Violet Adsorption by Oppositely Twisted Heat-Treated Halloysite and Pecoraite Nanoscrolls. Appl. Clay Sci. 2019, 173, 1-11. [CrossRef]

35. Belkassa, K.; Khelifa, M.; Batonneau-Gener, I.; Marouf-Khelifa, K.; Khelifa, A. Understanding of the Mechanism of Crystal Violet Adsorption on Modified Halloysite: Hydrophobicity, Performance, and Interaction. J. Hazard. Mater. 2021, 415, 125656. [CrossRef]

36. Rozza, R.; Ferrante, F. Computational Study of Water Adsorption on Halloysite Nanotube in Different PH Environments. Appl. Clay Sci. 2020, 190, 105589. [CrossRef]

37. ASTM. Standard Tables for Reference Solar Spectral Irradiances: Direct Normal and Hemispherical on $37^{\circ}$ Tilted Surface; ASTM International: West Conshohocken, PA, USA, 2013; pp. 1-21. [CrossRef]

38. Albdiry, M.T.; Yousif, B.F. Morphological Structures and Tribological Performance of Unsaturated Polyester Based Untreated/Silane-Treated Halloysite Nanotubes. Mater. Des. 2013, 48, 68-76. [CrossRef]

39. Grum, F.; Witzel, R.F.; Stensby, P. Evaluation of Whiteness. J. Opt. Soc. Am. 1974, 64, 210-215. [CrossRef] [PubMed]

40. Zhu, H.; Du, M.; Zou, M.; Xu, C.; Fu, Y. Green Synthesis of Au Nanoparticles Immobilized on Halloysite Nanotubes for Surface-Enhanced Raman Scattering Substrates. Dalt. Trans. 2012, 41, 10465-10471. [CrossRef] [PubMed]

41. Yuan, P.; Southon, P.D.; Liu, Z.; Green, M.E.R.; Hook, J.M.; Antill, S.J.; Kepert, C.J. Functionalization of Halloysite Clay Nanotubes by Grafting with $\gamma$-Aminopropyltriethoxysilane. J. Phys. Chem. C 2008, 112, 15742-15751. [CrossRef]

42. Bordeepong, S.; Bhongsuwan, D.; Pungrassami, T.; Bhongsuwan, T. Characterization of Halloysite from Thung Yai District, Nakhon Si Thammarat Province, in Southern Thailand. Songklanakarin J. Sci. Technol. 2011, 33, 599-607.

43. Zatta, L.; da Costa Gardolinski, J.E.F.; Wypych, F. Raw Halloysite as Reusable Heterogeneous Catalyst for Esterification of Lauric Acid. Appl. Clay Sci. 2011, 51, 165-169. [CrossRef]

44. Mehraban, Z.; Farzaneh, F.; Shafiekhani, A. Synthesis and Characterization of a New Organic-Inorganic Hybrid NiO-Chlorophylla as Optical Material. Opt. Mater. 2007, 29, 927-931. [CrossRef]

45. Kohno, Y.; Totsuka, K.; Ikoma, S.; Yoda, K.; Shibata, M.; Matsushima, R.; Tomita, Y.; Maeda, Y.; Kobayashi, K. Photostability Enhancement of Anionic Natural Dye by Intercalation into Hydrotalcite. J. Colloid Interface Sci. 2009, 337, 117-121. [CrossRef] [PubMed] 